\title{
Effect of Parents Education on Child's Oral Health
}

\author{
AM Aurangjeb ${ }^{1}$, T Zaman' ${ }^{2}$, Shah $^{3}$
}

\begin{abstract}
Children under the age of 12 years generally spend most of their time with their parents and guardians even when they attend schools. It has been found that young children's oral health maintenance and outcomes are influenced by their parent's knowledge and beliefs, and knowledge and beliefs are influenced by their educational background. This study was done to assess the relation between parent's education and their child's oral health. Parents of children aged 3-12 years, attending The Dhaka Project School, Dokkhin Khan, Uttara, Dhaka were invited to participate in the study. A 17-item questionnaire covering socio-demographic characteristics, dietary practices and oral hygiene practices was distributed to their parents and a 8 item checklist was used during their visit to the school. Responses of the parents and findings of oral health of children were recorded. The sample comprised of 251 parents either mother or father, with the mean age of children being 5.65 years. Mean plaque index 1.60, calculus index 1.30, gingivitis index 1.11, decayed teeth index 1.69, missing teeth index 0.22 and filled teeth index was 0.07 . Parents with higher educational qualification and information gained through dentist had a better knowledge about child's oral health.
\end{abstract}

Keywords: Parents education, Child's oral health.

\section{Introduction}

Education has an effect on general health maintenance, as well as oral health. There is a dearth of information on the oral health of school children in Bangladesh. Very few information are available on the oral health of school children. Data from NOHS 2000 reported a mean Decayed Missing Filled Teeth (DMFT) of 1.40 in India, ${ }^{1}$ and developed countries in Europe, North America and Australia. ${ }^{2}$ Dental caries is a transmissible infectious disease in which Streptococcus mutans is generally considered to be the main etiological agent. ${ }^{3}$ Studies using phenotyping and/or genotyping methods strongly suggest that mother is the major primary source of infection for children.

1. Dr. Aslam Md. Aurangjeb, Lecturer, Department of Dental Public Health, Bangladesh Dental College and Hospital, Dhaka

2. Dr. Tamanna Zaman, Assistant Professor and Head, Department of Dental Public Health, Bangladesh Dental College and Hospital, Dhaka

3. Dr. Saiquat Shah, Lecturer, Department of Dental Public Health, Bangladesh Dental College and Hospital, Dhaka

\section{Address of correspondence:}

Dr. Aslam Md Aurangjeb, Lecturer, Department of Dental Public Health, Bangladesh Dental College and Hospital E-mail: drprince@gmail.com
Improper feeding practices by mothers/caregivers increase the risk for the development of early childhood caries in infants and toddlers, by promoting the early establishment of S. mutans in the oral cavity. ${ }^{3}$

Children under the age of 12 years generally spend most of their time with parents and guardians, especially mothers. These early years involve "primary socialization" during which the earliest childhood routines and habits are acquired. ${ }^{2}$ These include dietary habits and healthy behaviors established as norms at home and are dependent on knowledge and behavior of parents and elder siblings. Studies have reported that poor attitude of parents toward oral health of infants and young children are associated with increased caries prevalence (Hind and Gregory, 1995). ${ }^{4}$

It has been found that the more positive is the parents' attitudes towards dentistry; the better will be the dental health of their children. ${ }^{5}$ Young children's oral health maintenance and outcomes are influenced by their parent's knowledge and beliefs, which affect oral hygiene and healthy eating habits. Without basic knowledge of caries risk factors, importance of the deciduous teeth and oral maintenance, it is difficult to employ effective disease preventive strategies. ${ }^{6}$ Parent's knowledge and positive attitude towards good dental care are very important in the preventive cycle.

The aim of this study was to assess parent's education and their effect on their school going children. 


\section{Materials and Methods}

The sampling frame for this study comprised of parents of the children aged between 3 and 12 years, attending The Dhaka Project School, Dokkhin Khan, Uttara, Dhaka. The school was chosen according to convenience sampling. This study followed a cross-sectional design with purposive sampling. A total of 251 parents along with their children participated in the study. A pretested questionnaire of 17 questions in Bengali was designed in order to assess the knowledge of the parents. Simultaneously children were examined with a checklist. Instruments used for the oral examination were Torch, Caries probe, Periodontal Probe, Dental mirror, Face mask, Hand gloves, and Cotton. The answers provided by parents and the results of their children's oral examination was entered in the computer. SPSS version 11.5 was used to analyze data. Results are shown in tables as follows:-

\section{Results}

Table 1: Mean age of parents along with their child and mean oral hygiene index

\begin{tabular}{|l|l|l|l|l|l|}
\hline Characteristics & $\mathrm{n}$ & Minimum & Maximum & Mean & Std. Deviation \\
\hline Age Parents & 251 & 21 & 55 & 38.81 & 0.71 \\
Age Child & 251 & 3 & 12 & 5.65 & 0.61 \\
Plaque Index & 251 & 0 & 3 & 1.60 & 0.65 \\
Calculus Index & 251 & 0 & 3 & 1.30 & 0.58 \\
Gingivitis Index & 251 & 0 & 3 & 1.11 & 0.36 \\
Decayed Teeth & 251 & 0 & 8 & 1.69 & 1.67 \\
Missing Teeth & 251 & 0 & 3 & 0.22 & 0.61 \\
Filled Teeth & 251 & 0 & 6 & 0.07 & 0.44 \\
\hline
\end{tabular}

Table 1 shows among participating 251 parents and 251 children mean age of parents $38.81 \pm 0.71$, mean age of children $5.65 \pm 0.61$, plaque index 1.60 , calculus index 1.30, gingivitis index 1.11, mean decayed teeth 1.69 , mean missing teeth 0.22 and mean filled teeth 0.07 .

Table 2: Distribution of parents according to their education and oral health problem of their children

\begin{tabular}{|c|l|l|l|l|l|l|l|}
\hline & \multicolumn{3}{|l|}{ Oral Health Problem } & \multicolumn{1}{l|}{ Total } \\
\cline { 1 - 5 } Parents education & bleeding gums & dental pain & both & none & does not know & others & \\
\hline below primary & 24 & 35 & 32 & 61 & 21 & 2 & 175 \\
& $13.7 \%$ & $20.0 \%$ & $18.3 \%$ & $34.9 \%$ & $12.0 \%$ & $1.1 \%$ & $100.0 \%$ \\
primary and above & 11 & 14 & 11 & 33 & 5 & 2 & 76 \\
& $14.5 \%$ & $18.4 \%$ & & $43.4 \%$ & $6.6 \%$ & $2.6 \%$ & $100.0 \%$ \\
\hline
\end{tabular}

Table 2 shows bleeding gum, dental pain and both; dental pain was higher in number among below primary parent's children.

Table 3: Distribution of parents according to their education and plaque index of their children

\begin{tabular}{|l|l|l|l|l|l|}
\hline \multicolumn{2}{|l|}{ Plaque Index } & Total \\
\hline Parents education & absent & mild & moderate & severe & \\
\hline below primary & 1 & 85 & 76 & 13 & 175 \\
& $0.6 \%$ & $48.6 \%$ & $43.4 \%$ & $7.4 \%$ & $100.0 \%$ \\
primary and above & 1 & 31 & 35 & 9 & 76 \\
& $1.3 \%$ & $40.8 \%$ & $46.1 \%$ & $11.8 \%$ & $100.0 \%$ \\
\hline
\end{tabular}

Table 3 shows that total plaque index was higher in number among below primary educated parent's children.
Table 4: Distribution of parents according to their education and calculus index their of children

\begin{tabular}{|l|l|l|l|l|l|}
\hline & \multicolumn{4}{|l|}{ Calculus index } & Total \\
\hline Parents education & absent & mild & moderate & severe & \\
\hline below primary & 2 & 128 & 34 & 11 & 175 \\
& $1.1 \%$ & $73.1 \%$ & $19.4 \%$ & $6.3 \%$ & $100.0 \%$ \\
primary and above & 0 & 57 & 16 & 3 & 76 \\
& $0.0 \%$ & $75.0 \%$ & $21.1 \%$ & $3.9 \%$ & $100.0 \%$ \\
\hline
\end{tabular}

Table 4 shows that total calculus index was higher in number among below primary educated parent's children.

Table 5: Distribution of parents according to their education and gingival index of their children

\begin{tabular}{|l|l|l|l|l|l|}
\hline & \multicolumn{3}{|l|}{ Gingivitis index } & Total \\
\hline Parents education & absent & mild & moderate & severe & \\
\hline below primary & 0 & 153 & 21 & 1 & 175 \\
primary and above & $0.0 \%$ & $87.4 \%$ & $12.0 \%$ & $0.6 \%$ & $100.0 \%$ \\
& 3 & 64 & 9 & 0 & 76 \\
& $3.9 \%$ & $84.2 \%$ & $11.8 \%$ & $0.0 \%$ & $100.0 \%$ \\
\hline
\end{tabular}

Table 5 shows that total gingival index was higher in number among below primary educated parent's children.

Table 6: Distribution of parents according to their education and decayed teeth index of their children

\begin{tabular}{|c|c|c|c|c|c|c|c|c|c|c|}
\hline \multirow[b]{2}{*}{ Parents education } & \multicolumn{9}{|c|}{ Decayed Teeth Index } & \multirow[t]{2}{*}{ Total } \\
\hline & absent & one & two & three & four & five & six & seven & eight & \\
\hline below primary & \begin{tabular}{|l|}
64 \\
$36.8 \%$
\end{tabular} & $\begin{array}{l}32 \\
18.4 \%\end{array}$ & \begin{tabular}{|l|}
32 \\
$18.4 \%$
\end{tabular} & \begin{tabular}{|l}
23 \\
$13.2 \%$
\end{tabular} & \begin{tabular}{|l|}
15 \\
$8.6 \%$
\end{tabular} & \begin{tabular}{|l}
6 \\
$3.4 \%$
\end{tabular} & \begin{tabular}{|l|}
0 \\
$0.0 \%$
\end{tabular} & \begin{tabular}{|l}
1 \\
$0.6 \%$
\end{tabular} & \begin{tabular}{|l|}
1 \\
$0.6 \%$
\end{tabular} & $\begin{array}{l}174 \\
100.0 \%\end{array}$ \\
\hline primary and & 20 & 13 & 13 & 15 & 10 & 2 & 1 & 2 & 0 & 76 \\
\hline & $26.3 \%$ & $17.1 \%$ & $17.1 \%$ & $19.7 \%$ & $13.2 \%$ & $2.6 \%$ & $1.3 \%$ & $2.6 \%$ & $.0 \%$ & $100.0 \%$ \\
\hline
\end{tabular}

Table 6 shows that total number of decayed teeth was higher in number among below primary educated parent's children.

Table 7: Distribution of parents according to their education and missing teeth index of their children

\begin{tabular}{|l|l|l|l|l|l|}
\hline \multicolumn{2}{|l|}{} & \multicolumn{3}{|l|}{ Missing Teeth Index } & Total \\
\hline Parents education & zero & one & two & three & \\
\hline below primary & 153 & 16 & 5 & 1 & 175 \\
primary and above & $87.4 \%$ & $9.1 \%$ & $2.9 \%$ & $0.6 \%$ & $100.0 \%$ \\
& 61 & 6 & 5 & 4 & 76 \\
& $80.3 \%$ & $7.9 \%$ & $6.6 \%$ & $5.3 \%$ & $100.0 \%$ \\
\hline
\end{tabular}

Table 7 shows that total number of missing teeth was higher in number among below primary educated parent's children.

Table 8: Distribution of parents according to their education and filled teeth index of their children

\begin{tabular}{|c|c|c|c|c|c|}
\hline & \multicolumn{4}{|c|}{ Filled Teeth Index } & \multirow[t]{2}{*}{ Total } \\
\hline Parents education & absent & one & two & three & \\
\hline & $\begin{array}{l}165 \\
94.8 \%\end{array}$ & \begin{tabular}{|l|}
$7.0 \%$ \\
\end{tabular} & $\begin{array}{l}1 \\
0.6 \%\end{array}$ & $\begin{array}{l}1 \\
0.6 \%\end{array}$ & \begin{tabular}{|l|}
174 \\
$100.0 \%$
\end{tabular} \\
\hline primary and above & 73 & 3 & 0 & 0 & 76 \\
\hline & $96.1 \%$ & $3.9 \%$ & $0.0 \%$ & $0.0 \%$ & $100.0 \%$ \\
\hline
\end{tabular}

Table 8 shows that total number of filled teeth was higher in number among below primary educated parent's children. 
Table 9: Distribution of parents according to their education and gingival index of their children

\begin{tabular}{|l|ll|l|}
\hline \multicolumn{2}{|c|}{} & \multicolumn{3}{|c|}{ DMFT } & Total \\
\hline Parents education & up to 3 & Above 3 & \\
\hline below primary & 144 & 31 & 175 \\
primary and above & $82.3 \%$ & $17.7 \%$ & $100.0 \%$ \\
& 58 & 18 & 76 \\
& $76.3 \%$ & $23.7 \%$ & $100.0 \%$ \\
\hline
\end{tabular}

Table 9 shows that total number of DMFT was higher in number among below primary educated parent's children.

\section{Discussion}

Oral health of the children is associated with oral health knowledge of their mothers/guardians, as oral health related habits (such as those related to oral hygiene and diet) are established during infancy and maintained throughout early childhood. ${ }^{7}$ Parents, especially mothers, function as role models for their children. This study provides important new data to the evidence base related to knowledge of parents towards oral hygiene of children. To our knowledge, there are very few Indian studies involving mother and children of this age group. The questionnaire particularly focused on education of parents and the check list on oral health status of their children.

\section{Conclusion}

Health professionals, who are the first to come into contact with expectant and new mothers, need to disseminate appropriate and accurate information about oral health care for infants, especially the use of nursing bottle at night, the value of tooth brushing and regular dental visits. A matter of high priority is therefore the development and implementation of wide-scale, long-term programs of health education and promotion for expectant new mothers.

\section{References}

1. National Oral Health Survey. Dental Council of India, New Delhi: 2002 -03.

2. Holm AK. Caries in pre-school children: international trends. J Dent 1990; 291-5.

3. Berkowitz RJ. Mutans streptococci acquisition and transmission. Peadiatr Dent 2006; 28:106-9.

4. Hinds K, Gregory JR. National diet and nutrition survey: Children aged $11 / 2$ to $4 \frac{1}{2}$ years. Report of dental survey. Vol. 2. London: HMSO; 1995.

5. Friedman LA, Mackler IG, Hoggard GJ, French CI. A comparison of perceived and actual dental needs of a selected group of children in Texas. Community Dent Oral Epidemiol 1976;4:89-93.

6. Finlayson TL, Siefert K, Ismail AI, Sohn W. Maternal self-efficacy and 1-5 year old children's brushing habits. Community Dent Oral Epidemiol 2007; 35:272-81.

7. Wendt LK, Hallonsten Al, Koch G, Birkhed D. Analysis of caries-related factors in infants and toddlers living in Sweden. Acta Odontol Scand 1996; 54:131-7. 